\title{
Eosinophilic Granuloma of Gastro-intestinal Tract Caused by Herring Parasite Eustoma rotundatum
}

\author{
B. STERRY ASHBY,* M.B., F.R.C.S. ; P. J. APPLETON, $\dagger$ M.B., B.S. \\ IAN DAWSON, $\ddagger$ M.D., M.R.C.P.
}

Brit. med. F., 1964, 1, 1141-1145

For over 25 years sporadic reports have been appearing in the literature of cases of eosinophilic granuloma arising in various parts of the gastro-intestinal tract. Kaijser (1937) described the first cases. In a search of the literature, which although extensive is not claimed to be exhaustive, 47 papers were found, describing a total of 89 cases. They occurred throughout the alimentary tract from pharynx to rectum, though the majority were in the stomach and small intestine, and they

* Surgical Registrar, Westminster Hospital and Medical School, London. † House-Surgeon, Westminster Hospital and Medical School, London. F Reader in Pathology, Westminster Hospital and Medical School, London. came from many countries in many different parts of the world. The essential details of these cases are recorded in Table I and Fig. 1.

The one feature common to all these case reports is the microscopical appearance of the lesion. No matter which part of the alimentary tract is involved, the histological description is the same-an oedematous connective-tissue stroma with an increase of capillaries and lymphatics, and showing a massive diffuse eosinophil-cell infiltration, usually confined to the submucosa but sometimes splitting the muscularis mucosae and spreading into the muscle layer. The mucosa is almost always intact.

Table I.-List of Published Cases, in Chronological Order

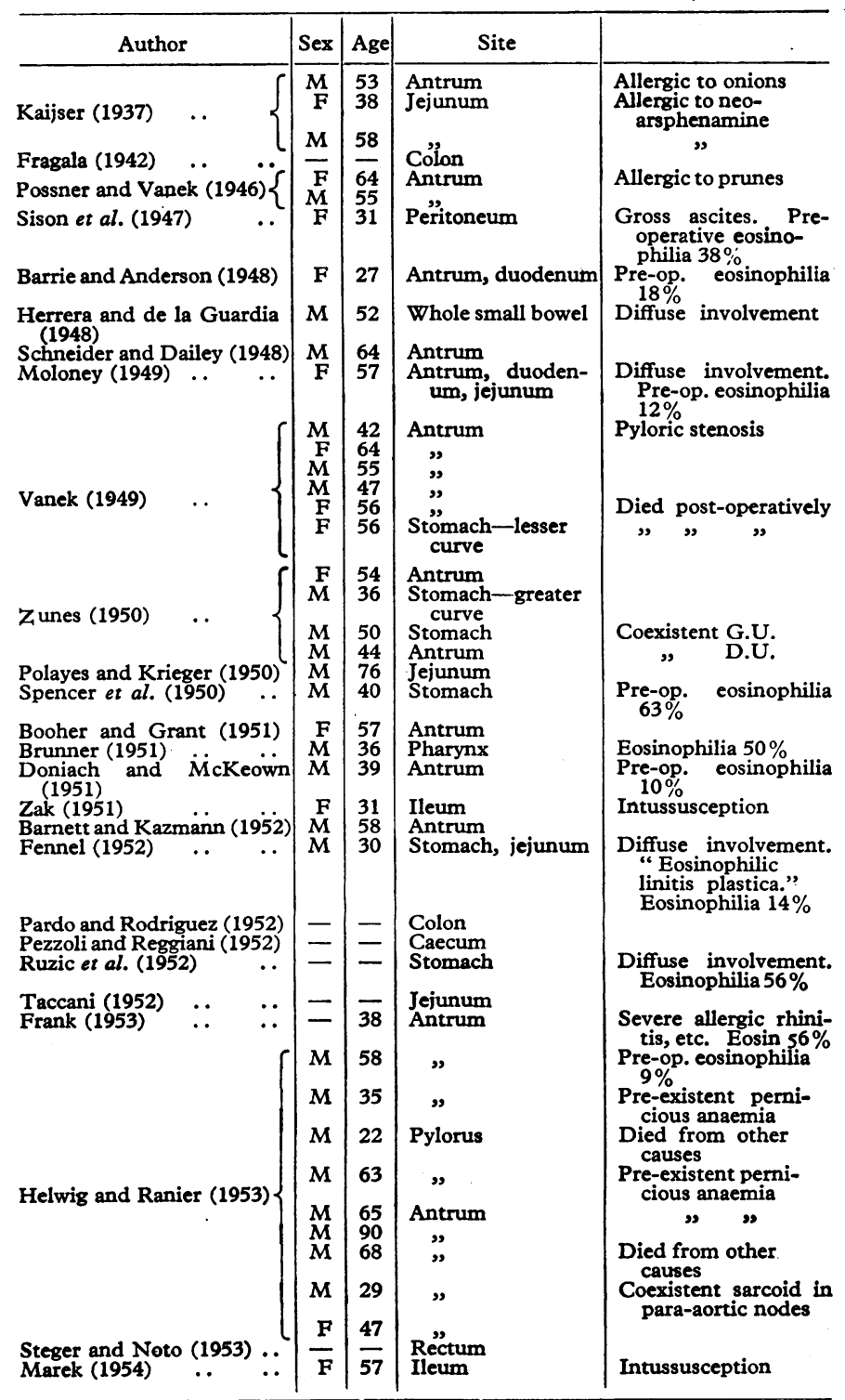

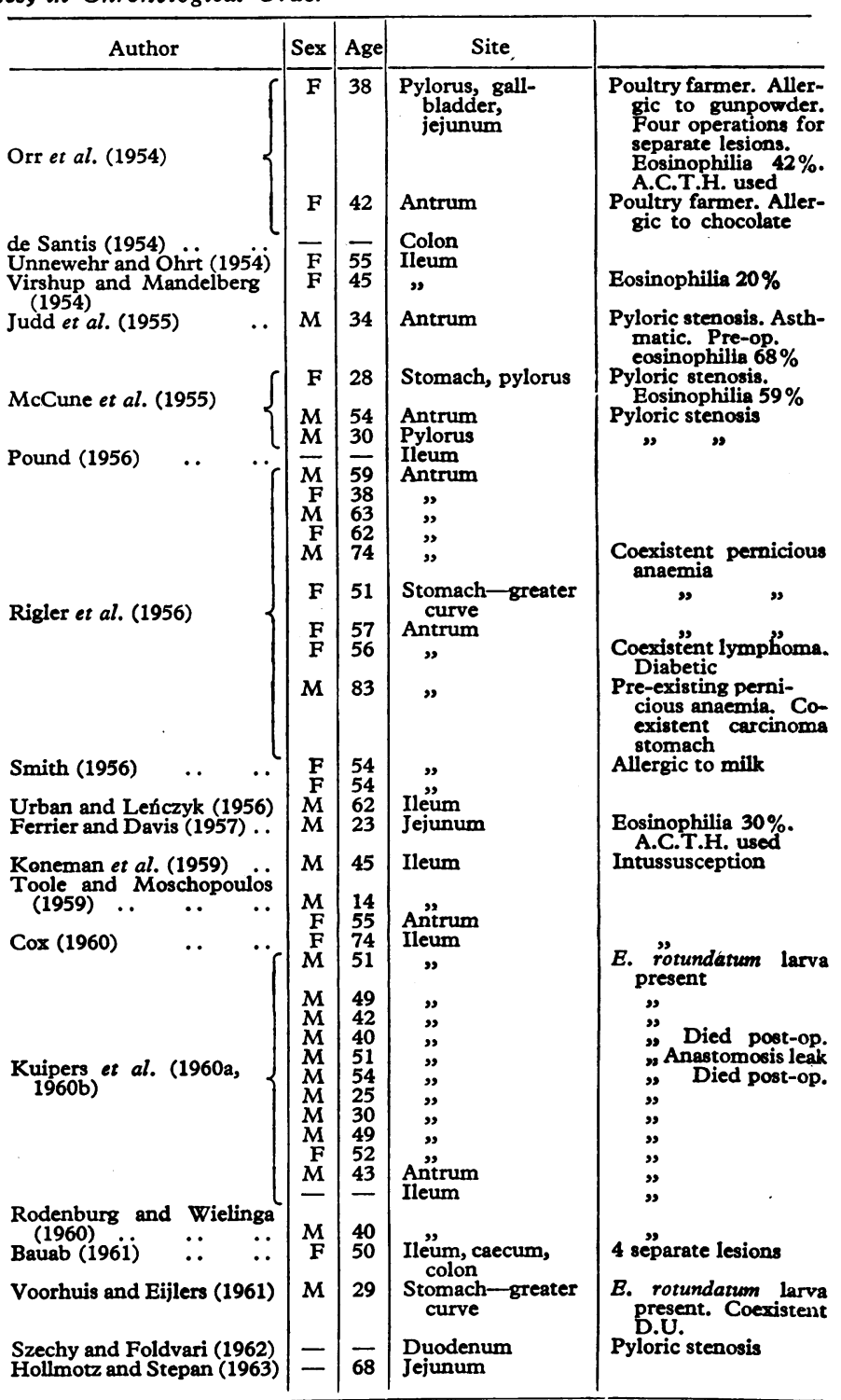


The aetiology of these lesions has been discussed by many authors, but until recently has remained obscure. Frequently it was suggested that the cause might well be an allergic reac-

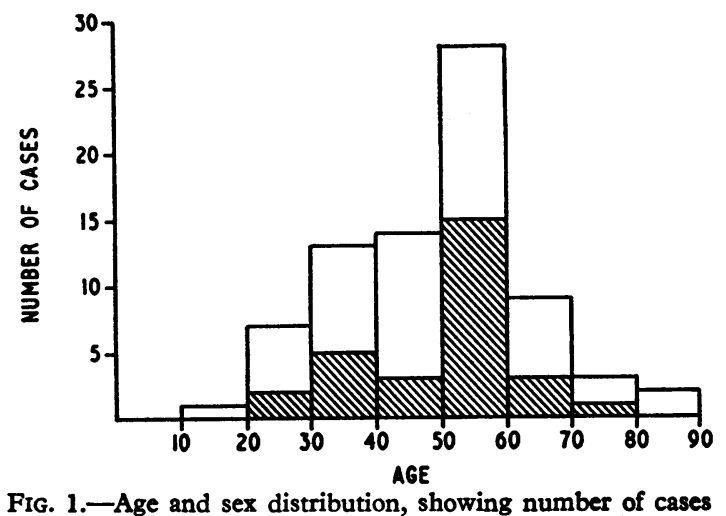

FIG. 1.-Age and sex distribution, showing number of
in each decade. (Hatched portion $=$ female.)

tion, possibly to some ingested foodstuffs. Some of the patients had an overt allergic history; of the three reported by Kaijser (1937) one was allergic to onions and two were syphilitics allergic to neoarsphenamine. Orr et al. (1954), in an excellent review of the subject, described two cases, one allergic to gunpowder, the other to chocolate; but perhaps the most significant thing about these patients is that they-were both poultry farmers. Others have been reported with an allergy to milk (Smith, 1956) and prunes (Possner and Vanek, 1946). Some have been asthmatics (Judd et al., 1955), and there are cases with a strong familial and constitutional tendency towards allergy, such as that described by Spencer et al. (1950), and Frank's (1953) patient who suffered from severe rhinitis and conjunctivitis.

Then in 1960 from Rotterdam came a series of papers describing 12 cases of eosinophilic granuloma of the small intestine and one of the stomach (Kuipers et al., 1960a, 1960b; Rodenburg and Wielinga, 1960). All the cases presented as abdominal emergencies, and in each the lesion was resected. The histological picture was again the eosinophilic phlegmon described so many times before; but in every specimen was found the remains of a larva which was identified as that of Eustoma rotundatum, a parasite commonly occurring in the peritoneum of the North Sea herring.

Kuipers and his colleagues investigated the parasite extensively, and found that it occurred in large numbers in the herring peritoneal cavity, the number present varying directly with the length of the herring. When the herring is caught, unless processed very soon after death, the parasite migrates from the peritoneum to the muscles. Freezing or salting slows down but does not arrest this migration, so that subsequent processing of the herring no longer eliminates the larvae which have shifted to the muscles. It is the habit of the Dutch populace, especially in the Rotterdam area, to eat these herrings raw or only slightly salted. It was felt that it was unlikely to be a simple infection which caused this characteristic lesion, or a great many more cases would have arisen, but rather an allergic reaction resulting from constant reinfection with the larva in a susceptible person.

It has been pointed out (Kuipers et al., 1960b) that raw or slightly salted herrings are eaten in countries other than the Netherlands, and that this may be the reason why cases of eosinophilic granulomata occur in other countries. We have recently seen two cases (reported in detail below) with the characteristic eosinophilic phlegmon in the small intestine, and, although the parasite was not located in either, the clinical and pathological picture was otherwise complete in both, and one of the patients was a fishmonger whose habit was to eat uncooked or slightly salted herrings and herring products.

It is not suggested that the herring parasite $E$. rotundatum is responsible for all the 89 reported cases of gastro-intestinal eosinophilic granulomata ; in some there is already a possible aetiological factor, and in others such a source is not a practical possibility; but in many of those occurring in western European territories it may well have been the causative agent.

\section{Case 1}

The patient, a healthy man aged 37, had been well apart from occasional episodes of abdominal colic during the previous year. Nine days before admission he had a severe attack of colic lasting for 12 hours and relieved by pethidine. A barium-meal examination after the attack showed a Meckel's diverticulum but no other radiological abnormality or evidence of obstruction. On the day of admission he had a further severe attack of colic without vomiting and with normal bowel action: by the time he reached hospital this had already subsided.

On examination his temperature was $98.4^{\circ} \mathrm{F} .\left(36.9^{\circ} \mathrm{C}\right.$.) and pulse 76. The abdomen was not tense or distended, there was no rigidity or guarding, or indeed any abnormal physical signs, and he appeared perfectly well. A diagnosis of intermittent obstruction due to a band associated with a Meckel's diverticulum was made, and laparotomy was performed the next day.

Operation (Mr. K. James).-A small Meckel's diverticulum was found. No band or obstruction was present, but the small intestine proximally was slightly dilated. The appendix appeared normal. About $45 \mathrm{~cm}$. proximal to the Meckel's diverticulum there was a sharply defined congested and oedematous segment of small intestine about $2 \frac{1}{2}$ in. $(6.4 \mathrm{~cm}$.) in length, covered with fibrin on the surface. The lymph nodes draining the segment were not enlarged. The affected segment was resected and an end-to-end anastomosis performed. The appendix and the Meckel's diverticulum were also resected. The patient made an uneventful recovery. After the histological sections had been examined (48 hours after operation), the white-cell count was 9,800 cells/c.mm., of which $7 \%$ were eosinophils. No pre-operative white-cell count is available. W.R. and Kahn test were negative and no history of allergy could be obtained.

Pathology.-The appendix was normal macroscopically and microscopically; no eosinophil infiltration was present. The Meckel's diverticulum was lined by small-intestinal epithelium. There was no ulceration, inflammation, or eosinophil infiltration microscopically. The third specimen consisted of $6 \mathrm{~cm}$. of ileum. The serosal surface was slightly congested and a patchy fibrinous exudate was present on it, but this was nowhere conspicuous. The mucosa did not appear to be ulcerated, but there was conspicuous thickening of the submucosa which had produced narrowing of the lumen (Fig. 2). Blocks from the whole length of the bowel were

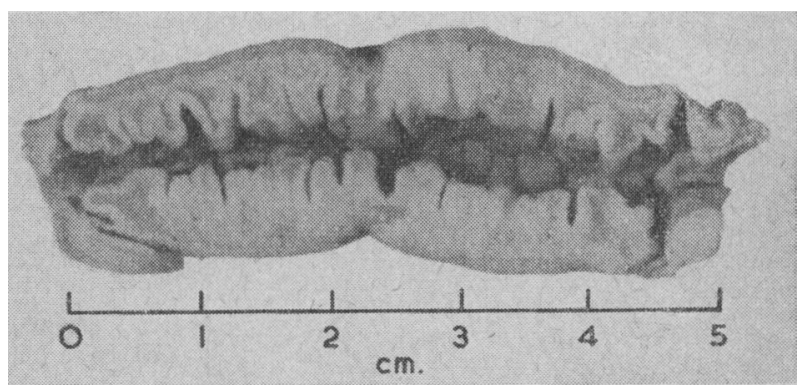

FIG. 2.-Resected segment of ileum from Case 1. Note the marked thickening of the bowel wall.

sectioned and examined microscopically. The general picture was the same throughout, though it varied in degree from section to section (Fig. 3). Mucosal ulceration was absent. The mucosa in the crypts appeared normal ; the villi were oedematous, with consequent shortening and broadening, and at their tips there was mucosal erosion. The submucosa was very oedematous and was heavily infiltrated with eosinophils: occasional mononuclear cells were also present, but there were no aggregates of mononuclear cells and no fibrosis. The muscle coats showed similar heavy eosinophil infiltration and there was oedema with eosinophil infiltration and early fibrosis in the serosal coat. In one place in the serosa a small artery was surrounded by eosinophils, but nowhere were vascular coats 
involved and arterial necrosis was not present. No follicular lymphoid tissue could be seen, and there was nothing to suggest tuberculosis, sarcoid, or Crohn's disease.

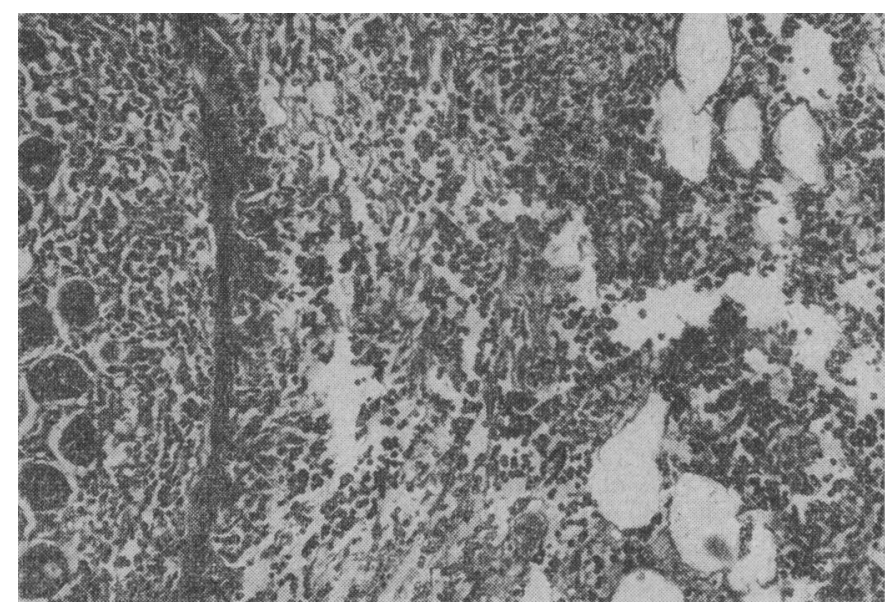

Fig. 3.--Inner mucosa, muscularis, and submucosa of Case 1, showing the inflammatory cellular infiltrate. The vast majority of the cells are eosinophils. (Haematoxylin and eosin. $\times 38$.)

\section{Case 2}

A man aged 60 was admitted to hospital as an emergency, in the early hours of the morning, with a two-days history of lower abdominal aching pain with superimposed episodes of colic. The pain had become increasingly severe since its onset, and shortly before admission the patient became nauseated and vomited several times. The bowels were regular and had been open the day before admission.

On examination he did not seem to be particularly ill but was clinically dehydrated, with loss of skin elasticity and a dry, coated tongue. The abdomen was moderately distended but not tympanitic. There was generalized tenderness with guarding, but no rebound tenderness. Bowel sounds were normal.

Investigations.- $\mathrm{Hb}, 14.2 \mathrm{~g} . / 100 \mathrm{ml}$. (96\%). Total W.B.C. $7,000 /$ c.mm. (neutrophils $73 \%$, eosinophils $1 \%$, lymphocytes $17 \%$, monocytes $9 \%$ ). Straight $x$-ray films of the abdomen showed a number of distended small-bowel loops containing fluid levels, particularly in the left upper quadrant.

A clinical diagnosis of low small-bowel obstruction was made. As the obstruction was subacute, with no evidence of strangulation, conservative treatment was instituted with intravenous fluids and gastric suction. At first there was some improvement in the clinical condition, but after 24 hours the abdominal distension had increased and rebound tenderness became evident. It was therefore decided that an exploratory laparotomy should be performed.

Operation (Mr. F. d'Abreu).-On opening the abdomen a small amount of straw-coloured free fluid was found in the peritoneal cavity. There was no obvious obstruction, but a segment of terminal ileum, approximately $4-5$ in. $(10-12.5 \mathrm{~cm}$.) in length, and about 12 in. $(30 \mathrm{~cm}$.) from the ileo-caecal valve, was found to be hyperaemic, reddish yellow in colour, thickened, and oedematous. The mesentery was also oedematous and contained a number of large lymph nodes. Owing to the unusual appearance and lack of evidence of obstruction, biopsies from the bowel wall, mesentery, and a lymph node were taken, but no other procedure was performed.

Post-operative Course.-Owing to the persistence of abdominal distension, intravenous fluids and gastric suction were continued. After three days the patient passed flatus as gastro-intestinal activity was re-established. The blood count. on the seventh post-operative day gave a total W.B.C. of 7,500/c.mm., with a normal differential and only $2 \%$ eosinophils. The stools were examined for ova, cysts, and larvae, but none were detected. Ten days after laparotomy a small-bowel barium-meal examination showed no abnormality. After the operation persistent glycosuria was noted and investigations showed the patient to be a mild diabetic. This was successfully controlled by a 12-line diet and chlorpropamide $250 \mathrm{mg}$./day.

Pathology.-The section of bowel wall showed an intense eosinophil infiltration in the mucosa and submucosa and extending throughout the muscle on to the serosal surface. In the fatty tissue there was an acute inflammatory reaction around the small blood-vessels, and the lymph node contained groups of eosinophils.

In view of the histological findings and the knowledge of recent case reports from Holland, the patient was questioned more carefully about his feeding habits. It was ascertained that he was in fact a fishmonger and during the course of the day had the habit of eating pieces of raw kipper or haddock. It was also discovered that in the past he had had a similar attack of abdominal pain which had settled spontaneously.

He was discharged from hospital three weeks after admission, symptom-free. He has been followed up regularly and when seen six months later remained well.

\section{Clinical Presentation}

\section{Discussion}

The clinical picture of eosinophilic granuloma varies, as might be expected, according to the site of occurrence in the gastro-intestinal tract. As Table II shows, in over $50 \%$ of the series the lesion occurred in the stomach. Most of these had a vague gastric history of variable length. Some presented as pyloric stenosis (Herrera and de la Guardia, 1948 ; Vanek, 1949 ; Szechy and Foldvari, 1962), and a few were symptomless, discovered during investigation of other conditions (Helwig and Ranier, 1953 ; Rigler et al., 1956).

TABLE II.-Distribution of Eosinophilic Granulomata in Gastro-intestinal Tract, Based on Total Number of Lesions (Including Each Separate Granuloma from Cases with Multiple Foci)

\begin{tabular}{|c|c|c|c|c|c|c|}
\hline Stomach & $\left\{\begin{array}{l}\text { Body } \\
\text { Antrum }\end{array}\right.$ & 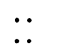 & $\ddot{0}$ & $\because$ & $\therefore$ & \\
\hline Small bowel & $\left\{\begin{array}{l}\text { Duodenum } \\
\text { Jejunum } \\
\text { Ileum }\end{array}\right.$ & $\ddot{\ldots}$ & $\ddot{x}$ & $\because$ & $\because$ & $\left.\begin{array}{r}1 \\
7 \\
24\end{array}\right]$ \\
\hline Large bowel & $\left\{\begin{array}{l}\text { Caecum } \\
\text { Colon } \\
\text { Rectum }\end{array}\right.$ & $\begin{array}{l}\cdots \\
\therefore\end{array}$ & $\begin{array}{l}\ldots \\
\ldots\end{array}$ & . & 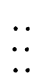 & $\left.\begin{array}{l}2 \\
5 \\
1\end{array}\right]$ \\
\hline Others & $\left\{\begin{array}{l}\text { Pharynx } \\
\text { Gall-bladder } \\
\text { Peritoneum } \\
\text { Generalized }\end{array}\right.$ & $\begin{array}{l}\ddot{ } \\
\text { diffuse }\end{array}$ & $\because \ddot{ }$ & $\begin{array}{l}. . \\
\therefore\end{array}$ & $\begin{array}{l}\ldots \\
\ldots \\
\ldots\end{array}$ & $\left.\begin{array}{l}1 \\
1 \\
1 \\
4\end{array}\right]$ \\
\hline
\end{tabular}

Of those with a phlegmon in the small bowel, most presented as a subacute incomplete small-bowel obstruction, as illustrated by Cases 1 and 2 . They were found to have a short length of thickened involved bowel in the jejunum or ileum which was slowly producing a constriction. There were some in which the lesion took the localized form of a polyp, and these presented more acutely as an intussusception (Zak, 1951; Marek, 1954 ; Koneman et al., 1959 ; Cox, 1960). In some cases of involvement of distal ileum it was difficult to distinguish them clinically from appendicitis (Kuipers et al., (1960b).

A few examples are also recorded in which a granulomatous polyp showing eosinophilic infiltration was an incidental finding at post-mortem examination on patients who died from other causes (Kofler, 1952; Feyrter, 1953). These have not been included in the review as they do not strictly belong to the clinical series.

$X$-ray examinations have not proved very helpful, but barium meals have sometimes demonstrated appearances such as a rigid pyloric antrum, peptic ulcer, antral polyp, pyloric stenosis, or suspected carcinoma, which have led to operation and to the discovery of the lesion.

\section{Pathology}

Macroscopic Appearances.-Eosinophilic granulomata of the gastro-intestinal tract can occur in two forms-diffuse, which may involve a long or a short segment, and localized, which may show either single or multiple lesions. The diffuse lesions in the stomach take the form of thickening of the antrum and pylorus, though a few showed thickening of the whole stomach (Fennel, 1952; McCune et al., 1955). The local lesions were 
often polypoid in the gastric antrum, and some were on long stalks and had passed right through the pylorus into the duodenum (Spencer et al., 1950 ; Booher and Grant, 1951 ; Rigler et al., 1956 ; Smith, 1956 ; Toole and Moschopoulos, 1959). The pylorus was thickened and oedematous in nearly all the gastric cases. Coexistent peptic ulcers were present in a few, and the granuloma formed a small tumour in the edges of a gastric ulcer in two of them (Vanek, 1949 ; Nunes, 1950).

In the small bowel the localized polyp occurred occasionally, and these were the cases presenting with intussusception. Most of the patients, however, showed the diffuse form, including our own two cases. The affected segment of bowel varied in length from a very short annular constriction (Polayes and Krieger, 1950 ; Virshup and Mandelberg, 1954) to a generalized thickening along almost the whole of the small intestine (Herrera and de la Guardia, 1948). In some patients the mesenteric lymph nodes were enlarged, as in our Case 2 . The intestine involved was thickened and oedematous, with dark yellow/red or red/blue discoloration, and loss of serosal sheen. We agree with the authors who have commented on the similarity in appearance with acute Crohn's disease (Moloney, 1949 ; Doniach and McKeown, 1951 ; Orr et al., 1954 ; Ferrier and Davis, 1957), and this possibility was in fact considered particularly at laparotomy in Case 2.

Two cases showed multiple well-localized areas of involvement. In that described by Bauab (1961) there were four lesions in the ileum, caecum, and colon. Orr et al. (1954) described the case of a young woman who had a characteristic lesion in the pyloric antrum excised, followed three years later by a cholecystectomy, the gall-bladder wall showing eosinophilic infiltration. A year after this she had a gastrectomy for a thickened pylorus with the same histology, and four months later a further laparotomy when the upper jejunum was found to be involved. A recurrence one year later was successfully treated with steroids.

In many patients, including both those described in this paper, a small amount of yellow ascitic fluid was found when the abdomen was opened. One case showed gross ascites with no apparent cause, associated with a high eosinophil content in the fluid and a $38 \%$ eosinophilia in the peripheral blood (Sison et al., 1947).

Histological Appearances.-The lesion is situated in the submucosa of the gastro-intestinal tract. It is characterized by a marked vascularity and oedema, with dilated lymphatics. The outstanding feature is a massive eosinophilic infiltration throughout this submucosal stroma. The overlying mucosa is usually intact, but occasionally is ulcerated (Moloney, 1949 ; Helwig and Ranier, 1953). The muscularis mucosae is involved, and split up by eosinophilic infiltration; sometimes the changes spread right through the muscle coats to the subserosa, but the serosa is always intact. Occasionally giant cells are seen, and a few plasma cells and lymphocytes. When any lymph nodes are involved they show a similar histological picture, dominated by sheets and groups of eosinophils. A careful search for parasites should always be made, using multiple sections.

\section{Aetiology}

It has often been postulated that gastro-intestinal eosinophilic granuloma may be an allergic phenomenon. The histological appearances show numerous eosinophils in the lesion. Yet in the whole collected series, out of 51 peripheral blood eosinophil counts recorded, only 15 were above $4 \%$ pre-operatively; nor was the eosinophil count raised in either of our cases. No other stigmata of a systemic allergic reaction have occurredexcept in those few patients, already cited, who have a strongly allergic constitution-and no sudden anaphylactic phenomenon has been encountered. These considerations suggest it is a local gastro-intestinal reaction to an ingested allergen rather than part of a systemic allergic reaction. As causative agents intestinal parasites are an obvious possibility, and Kuipers and his colleagues (1960a, 1960b) were able to demonstrate the remains of the larva of the herring parasite $E$. rotundatum in the bowel wall in every one of their 13 cases.

As Kuipers has pointed out, if the cause were a simple infection with the parasite many more than the few recorded cases would have occurred. The comparative rarity of the condition suggests that repeated exposure to infection is necessary and an immune state is gradually acquired, the chronic granuloma being a local tissue allergic response.

We do not suggest that all cases of eosinophilic granuloma of the gut are due to eating uncooked or slightly salted North Sea herring (known in this country as " roll-mops"). This would be unreasonable, because cases have occurred all over the world. But the responsible agent may be the ova or larvae of one of a number of different parasites contaminating animal food products, varying with the geographical area. One patient from Honolulu was known to be harbouring at least three different worms (Fennel, 1952). Both the patients described by Orr et al. (1954) were poultry farmers. And in the North Sea countries the raw herring, a known host of $E$. rotundatum, is consumed widely.

A number of conditions have been found coexistent with eosinophilic granuloma, but mostly only in single cases and not connected aetiologically (see Table I). But a macrocytic anaemia has occurred in no fewer than six patients before they developed the granuloma (Helwig and Ranier, 1953 ; Rigler et al., 1956), which is a higher proportion than would be expected by chance among just under 90 cases. It is suggested that this may not have been true pernicious anaemia, but the macrocytic anaemia that develops in association with chronic or recurrent gastro-intestinal parasitic infestation.

Although the parasite has not actually been demonstrated in either of the patients presented in this paper, nevertheless we feel they fit the clinical and pathological picture of small-bowel eosinophilic granuloma caused by $E$. rotundatum, and one of the patients was a fishmonger who confessed to the habit of consuming raw fish.

\section{Treatment}

There is no specific treatment to offer for this condition. The lesion has been resected in nearly all the cases described, mainly because the diagnosis is a histological one and is made in retrospect. Two deaths are recorded as occurring after gastrectomy for gastric granulomata (Vanek, 1949). Lesions in the small bowel also have nearly all been resected, with anastomosis, and two deaths have occurred after this, and at least one peritonitis from a leaking anastomosis (Kuipers et al., 1960a).

In such a transient, benign, and eminently reversible condition as this allergic manifestation no morbidity or mortality should result from treatment. The deaths following major resections suggest that perhaps more conservative treatment is indicated. If for mechanical reasons it is necessary to resect for a polyp near the pylorus, then a simple polypectomy should be considered rather than a gastrectomy. But whenever possible, especially in small-bowel cases, no more than a biopsy should be carried out to confirm the diagnosis.

Steroids provide the most rational approach to conservative treatment, and are suggested by Kuipers et al. (1960b). A.C.T.H. has in fact been used on two occasions with success (Orr et al., 1954 ; Ferrier and Davis, 1957). Supportive treatment may sometimes be required, such as intravenous fluids and gastric aspiration in cases of small-bowel granulomata producing temporary obstruction. Case 2, described above, did not have a resection performed, but settled down in a few days on general supportive management and did not even require steroids. 


\section{Summary}

Reports of eosinophilic granulomata in the gastro-intestinal tract have been appearing for over 25 years, but until recently the aetiology of these lesions has remained obscure. There is now evidence that at least some cases, especially those occurring in Western Europe, may be caused by the parasite Eustoma rotundatum, which commonly occurs in North Sea herrings, and may be ingested in uncooked or salted herring products, such as " roll-mops."

The cases of two patients with an eosinophilic granuloma of the small intestine are reported, one of whom is a fishmonger.

A series of 89 cases, with a total of 96 lesions, collected from the literature are reviewed. In about half the cases the lesion was in the stomach or pyloric antrum, and presented with gastric or pyloric symptoms. In a further third the small intestine was involved, causing intestinal obstruction.

The granuloma may occur in two forms, diffuse or localized. The histological features are described. Aetiology is discussed, and it is is suggested that eosinophilic granuloma represents a local allergic response to $E$. rotundatum, due to an immune state acquired by repeated reinfection with the parasite.

There is no specific treatment, but the prognosis is good, and conservative management is advocated rather than major resections whenever possible. Steroids have been used on several occasions.

We wish to thank Mr. F. d'Abreu, surgeon to the Westminster Hospital, and Mr. K. L. James, lately surgeon to the Gordon Hospital, for permission to publish reports of cases under their care.

\section{REFERENCES}

Barnett, L. A., and Kazmann, H. A. (1952). Amer. f. Surg., 84, 107.

Barrie, H. J., and Anderson, J. C. (1948). Lancet, 2, 1007.

Bauab, E. G. (1961). Pren. méd. argent., 48, 1311.

Booher, R. J., and Grant, R. N. (1951). Surgery, 30, 388.

Brunner, H. (1951). Oral Surg., 4, 623.

Cox, J. S. T. (1960). Brit. F. Surg., 48, 149.

Doniach, I., and McKeown, K. C. (1951). Ibid., 39, 247.
Fennel, E. A. (1952). Proc. Straub Clin. (Honolulu), 18, 69.

Ferrier, T., and Davis, N. (1957). Med. 7. Aust., 1, 789.

Feyrter, F. (1953). Arch. klin. Chir., 274, 320.

Fragala, G. (1942). Boll. Soc. med.-chir. Catania, 10, 339

Fragala, G. (1942). Boll. Soc. med.-chir. Catania, 10,

Helwig, E. B., and Ranier, A. (1953). Surg. Gynec. Obstet., 96, 355.

Herrera, J. M., and de la Guardia, J. (1948). Arch. Hosp. S. Tomás (Panamá), 3, 19.

Hollmotz, O., and Stepan, Z (1963). Cs. Rentgenol., 17, 65.

Judd, C. S., Civin, W. H., and McIlhany, M. L. (1955). Gastroenterology, $28,453$.

Kaijser, R. (1937). Arch. klin. Chir., 187, 351.

Kofler, E. (1952). Virchows. Arch. path. Anat., 321, 121.

Koneman, E. W., Sawyer, K. C., and Lubchenco, A. E. (1959). Arch. Surg., 78, 923.

Kuipers, F. C., VanThiel, P. H., and Roskam, E. T. (1960a). Ned. T. Geneesk., 104, 422.

- Rodenburg, W., Wielinga, W. J., and Roskam, R. T. (1960b). Lancet, 2, 1171 .

McCune, W. S., Gusack, M., and Newman, W. (1955). Ann. Surg., 142, 510.

Marek, S. (1954). Cas., Lék. česk., 93, 484.

Moloney, G. E. (1949). Lancet, 1, 412.

Nunes, M. A. (1950). Gaz. méd. port., 3, 751.

Orr, I. M., Miller, A. A., and Russell,' J.'Y. W. (1954). Postgrad. med. f., 30, 485 . Pardo, M.' V., and Rodriguez, T. I. (1952). Arch. Hosp. univ. (Habana),
4, 248 .

Pezzoli, A., and Reggiani, E. (1952). Arch. ital. Mal. Appar. dig., 18, 97.

Polayes, S. H., and Krieger, J. L. (1950). F. Amer. med. Ass., 143, 549.

Possner, M.; and Vanek, J. (1946). Cas. Lék. ¿esk., 85, 685.

Pound (1956). Personal communication: cited by Ferrier and Davis (1957).

Rigler, L. G., Blank, L., and Hebbel, R. (1956). Radiology, 66, 169.

Rodenburg, W., Wielinga, W. J. (1960). Ned. T. Geneesk., 104, 417.

Ruzic, J. P., Dorsey, J. M., Huber, H. L., and Armstrong, S. H. (1952). f. Amer. med. Ass., 149, 534.

de Santis, M. (1954). Polyclinico, Sez. prat., 61, 1521.

Schneider, H., and Dailey, M. E: (1948). Gastroenterology, 10, 727.

Sison, A. B. M., Dionisio, S. A., Silva, J. A., and Chavez, P. C. (1947). 7. Amer. med. Ass., 134, 1007.

Smith, M. J. (1956). Radiology, 66, 177.

Spencer, J. R., Comfort, M. W., and Dahlin, D. C. (1950). Gastroenterology, 15, 505 .

Steger, C., and Noto, L. (1953). Acta chir. patav., 9, 339.

Szechy, M., and Foldvari, G. (1962). Orv. Hetil., 103, 501.

Taccani, C.' (1952). Excerpta med. (Amst.), 1953, Sect. IX, No. 7650.

Toole, H. J., and Moschopoulos, A. N. (1959). Brit. F. Surg., 46, 445.

Unnewehr, F., and Ohrt, H. (1954). Zbl. Chir., 79, 91.

Urban, A., and Leńczyk, M. (1956). Pat. pol., 7, 307.

Vanek, J.' (1949). Amer. F. Path., 25, 397.

Virshup, M., and Mandelberg, A.' (1954). Ann. Surg., 139, 236

Voorhuis, F. J., and Eijlers, W. (1961). Ned. T. Geneesk., 105, 2542.

Zak, R. (1951). Lék. Listy, 6, 73.

\title{
Effect of Hypnosis on Allergic Skin Responses in Asthma and Hay-fever
}

\author{
LIONEL FRY,* M.B., B.SC., M.R.C.P. ; A. A. MASON,* M.B., в.S. ; R. S. BRUCE PEARSON,* D.M., F.R.C.P.
}

Brit. med. F., 1964, 1, 1145-1148

Hypnosis has been reported to be of therapeutic value in asthma (Asher, 1956 ; Stewart, 1957 ; Mason, 1960 ; Fry, 1957 ; Edwards, 1960 ; Maher-Loughnan et al., 1962) and in hay-fever (Mason, 1960).

The effect of hypnosis on the allergic skin responses has been investigated only on isolated subjects (Mason and Black, 1958) and recently on selected good hypnotic subjects (Black, 1963a, 1963b). It was considered important to investigate the effect of hypnosis on a direct allergic cutaneous response, and so help to elucidate the mechanism of action of the reported benefit offered by hypnosis to asthmatic and hay-fever patients.

\section{Material and Method}

Forty-seven subjects who had asthma and/or hay-fever and who had positive skin reactions to extracts of pollen or house- dust were included in the study. Three patients who could not be hypnotized were excluded.

The skin-testing was carried out by means of the prick-test. Four strengths of the extract were used on each arm. The first strength in the pollen cases contained 10,000 units in a preservative " tween 80 ," the second strength 1,000 units, and the third strength 100 units, and the fourth 10 units. In the case of house-dust extract the first strength was a commercial standard skin-test preparation, and the other strengths were dilutions of $1 / 10,1 / 100$, and $1 / 1000$ as with pollacine.

Each subject was tested on the anterior surface of both forearms with the four strengths of the allergen under test. Prior to hypnosis the tests were performed at 2, 7, 12, and $17 \mathrm{~cm}$. from the antecubital fossa, and after hypnosis at 4,9 ,

\footnotetext{
- From King's College Hospital, London.
} 